University of Nebraska - Lincoln

DigitalCommons@University of Nebraska - Lincoln

6-22-2016

\title{
A spatio-temporal comparison of avian migration phenology using Citizen Science data
}

\author{
Ali Arab \\ Jason R. Courter \\ Jessica Zelt
}

Follow this and additional works at: https://digitalcommons.unl.edu/usgsstaffpub

Part of the Geology Commons, Oceanography and Atmospheric Sciences and Meteorology Commons, Other Earth Sciences Commons, and the Other Environmental Sciences Commons

This Article is brought to you for free and open access by the US Geological Survey at DigitalCommons@University of Nebraska - Lincoln. It has been accepted for inclusion in USGS Staff -- Published Research by an authorized administrator of DigitalCommons@University of Nebraska - Lincoln. 


\title{
A spatio-temporal comparison of avian migration phenology using Citizen Science data
}

\author{
Ali Arab ${ }^{\mathrm{a}, *}$, Jason R. Courter ${ }^{\mathrm{b}}$, Jessica Zelt ${ }^{\mathrm{c}}$ \\ ${ }^{a}$ Department of Mathematics and Statistics, Georgetown University, 37 th and $O$ streets, Washington, \\ DC 20057, USA \\ ${ }^{\mathrm{b}}$ Department of Science and Mathematics, Malone University, 2600 Cleveland Ave. NW, Canton, \\ OH 44709, USA

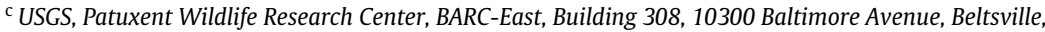 \\ MD 20705, USA
}

\section{A R T I C L E I N F O}

\section{Article history:}

Received 31 December 2015

Accepted 15 June 2016

Available online 22 June 2016

\section{Keywords:}

Spatial analysis

Hierarchical Bayesian models

Markov chain Monte Carlo

Ornithology

Climate change

\begin{abstract}
A B S T R A C T
The effects of climate change have wide-ranging impacts on wild life species and recent studies indicate that birds' spring arrival dates are advancing in response to changes in global climates. In this paper, we propose a spatio-temporal approach for comparing avian first arrival data for multiple species. As an example, we analyze spring arrival data for two long-distance migrants (Rubythroated Hummingbird Archilochus colubris; and Purple Martin Progne subis) in eastern North America from 2001-2010 using Citizen Science data. The proposed approach provides researchers with a tool to compare mean arrival dates while accounting for spatial and temporal variability. Our results show that on average, Purple Martins arrive 29.95 to 31.84 days earlier than Ruby-throated Hummingbirds, but after accounting for this overall difference, spatial nuances exist whereby martins arrive earlier in the southern United States and migrate northward at a slower rate than hummingbirds. Differences were also noted in how climate and weather variables such as the North Atlantic Oscillation index, winter temperature, winter-spring precipitation, sampling effort, and altitude impacted migration dates. Our method may easily be generalized to analyze a broad range of temporal and spatial Citizen Scientists data to help better understand the ecological impacts of climate change.
\end{abstract}

(C) 2016 Elsevier B.V. All rights reserved.

\footnotetext{
* Corresponding author.

E-mail address: aa577@georgetown.edu (A. Arab).
} 


\section{Introduction}

The effects of climate change are apparent and have wide-ranging impacts on wildlife species (Parmesan and Yohe, 2003). Advancements in spring events, poleward range shifts, and changing interactions among species have been predicted (Matthews et al., 2011) and demonstrated (McKinney et al., 2012). In many cases, birds are sentinels of change and many studies have reported that avian migration dates have advanced in response to changes in global climates (Møller et al., 2010; Knudsen et al., 2011). These advancements have been correlated with changes in temperature (Courter et al., 2013a; Hurlbert and Liang, 2012), precipitation (Studds and Marra, 2011), and large-scale climate indices such as the North Atlantic Oscillation (NAO) index (Gordo et al., 2011).

Not only are the life history characteristics of many birds suitable for detecting potential climaterelated impacts (e.g., birds are volant, migratory, and highly responsive to environmental changes), but birds are also popular among naturalists and continental-scale monitoring programs for birds have been in place in North America since the 1880s (Zelt et al., 2012). Today, smartphones and associated web-based platforms make it easier than ever for groups of Citizen Scientists to contribute data to field-based phenology studies (Sullivan et al., 2014). One advantage of assessing changes in avian arrival dates using Citizen Science data is the ability of researchers to understand ecological processes at broader spatial scales (Knudsen et al., 2011). Traditional bird phenology studies have been conducted at broad temporal but narrow spatial scales (Ledneva et al., 2004; Swanson and Palmer, 2009). While there are benefits to site-based approaches (e.g., the ability to reduce observer error, to utilize consistent weather data, etc.), inferences are limited spatially and may not account for the spatial variability of ecological process such as climate change (Primack et al., 2009). Data collected at broad spatial scales are especially important for assessing changes in arrival dates of long-distance migrants that sometimes fly thousands of kilometers between breeding and wintering grounds during their annual cycles (Hostetler et al., 2015).

At a time when long-term migration data and climate data are becoming increasingly available for use by researchers (e.g., through programs such as the North American Bird Phenology Program, eBird, etc.), large-scale comparisons of migratory changes at broad temporal and spatial scales are beginning to emerge (Hurlbert and Liang, 2012), although most studies assess migratory changes for a particular species (e.g., Courter et al., 2013a, Laughlin et al., 2013, Arab and Courter, 2015). Therefore, the objective of our study is to provide a technique for comparing migratory changes among species. As an example, we demonstrate a spatio-temporal comparison of two long-distance migrants in parts of the eastern United States from 2000 to 2010 to elucidate potential differences in the effects of spatial and climate variables on the timing of migration. Our proposed model provides a straightforward exploratory data analysis tool for inferential purposes as well as for predictive modeling.

\section{Materials and methods}

\subsection{Focal species}

Ruby-throated Hummingbirds (Archilochus colubris) winter in Central America and migrate across the Gulf of Mexico between February and May to their breeding grounds in eastern North America. They feed primarily on nectar and small insects during migration (Robinson et al., 1996). Purple Martins (Progne subis) winter in South America and migrate to North America between February and May, with male "scouts" often arriving several weeks before females to look for suitable breeding territories (Tarof and Brown, 2013). Martins are aerial insectivores and arrive in North America approximately one month earlier than hummingbirds (Tarof and Brown, 2013; Courter et al., 2013a). For the purposes of our study, we considered both species to be "long-distance" migrants because they regularly winter outside of the United States (Butler, 2003).

\subsection{First arrival and weather data}

We use first arrival data for these species from two Citizen Science programs: First arrival dates of Ruby-throated Hummingbirds from 2001 to 2010 were reported by Citizen Science volunteers 
through hummingbirds.net and Journey North, and were accessed from the Journey North online database (https://www.learner.org/jnorth/; for additional details, see Courter et al., 2013a). Purple Martin data from 2001 to 2010 were collected by a similar network of volunteer naturalists from the Purple Martin Conservation Association (PMCA; www.purplemartin.org; for additional details, see Arab and Courter, 2015). To approximate weather conditions associated with each first arrival report, we used weather data from the National Oceanic and Atmospheric Administration Time Bias Corrected Divisional Temperature-Precipitation-Drought Index data set reported by climate division. We included spatial and climatic variables in our analysis that had previously been linked to changes in first arrival dates such as temperature, precipitation, winter (December-March) values of the North Atlantic Oscillation Index (WNAO), and altitude, and kept variables in our final models that explained significant variation for either hummingbirds or martins. See Supplementary File for further details about the variables (see Appendix A).

We then developed a grid system to aggregate first arrival dates (given as day-of-the-year with January 1st as "1") by year and species. First arrival dates were most consistently reported in midlatitudes of North America (i.e., between $32-41^{\circ} \mathrm{N}$, and $95-80^{\circ} \mathrm{W}$ ) throughout our study, so for each degree of latitude between $32^{\circ}$ and $41^{\circ} \mathrm{N}$, arrival dates were grouped into one of three $5^{\circ}$ longitude bands (i.e., $94.99^{\circ} \mathrm{W}-90.0^{\circ} \mathrm{W}, 89.99^{\circ} \mathrm{W}-85.0^{\circ} \mathrm{W}$, and $84.99^{\circ} \mathrm{W}-80.0^{\circ} \mathrm{W}$ ). Setting up a grid in this manner ensured that $\geq 5$ observations were available in each grid cell (total of 30 grid cells) for each species/year combination. We calculated a mean first arrival date for each grid cell, year, and species combination.

\subsection{Hierarchical spatio-temporal modeling}

We used a hierarchical modeling approach to account for spatial and temporal variability in the data. Hierarchical modeling has become increasingly popular in ecological and environmental studies due to their flexibility for handling complex data (Clark, 2005; Wikle, 2003). In a hierarchical model, a complex problem is decomposed into a series of simpler sub-problems linked by rules of conditional probability (Berliner, 1996; Arab et al., 2008). This flexible modeling approach allows the analyst to simultaneously account for data sampling variability, parameter uncertainty, and potential dependence structures such as spatial and temporal structures.

Let $\mathbf{Y}_{j, t}=\left(Y_{1, j, t}, \ldots, Y_{n, j, t}\right)^{\prime}$ denote the vector of mean arrival dates for the $j$ th species $(j=1, \ldots, J$; $J=2$ in our case, ) for the grid cells $(i=1, \ldots, n ; n=30$ in our case) over years in the study ( $t=1$, $\ldots, T ; T=10$ for years 2001-2010) where $Y_{i, j, t}$ represent the mean arrival dates for the $j$ th species, for the $i$ th grid cell in the $t$ th year. Using a hierarchical modeling framework (Berliner, 1996) which relies on three stages of Data, Process, and Parameter Models, we define the following Data Models for the Purple Martins and Ruby-throated Hummingbirds

$$
\mathbf{Y}_{j, t} \sim N\left(\mathbf{m}_{j, t}, \mathbf{D}_{j, t}\right), \quad \text { for } j=1,2,
$$

where $\mathbf{m}_{j, t}=\left(m_{1, j, t}, \ldots, m_{n, j, t}\right)^{\prime}$ denotes the vector of the mean arrival process, and $\mathbf{D}_{j, t}=$ $\operatorname{diag}\left(\sigma_{1, j, t}^{2}, \sigma_{2, j, t}^{2}, \ldots, \sigma_{n, j, t}^{2}\right)$ denotes the error variance-covariance matrix for the $j$ th species $(j=1,2$; our arbitrary notation uses 1 for Purple Martin, and 2 for Ruby-throated Hummingbird) and year $t$. Here, the observed mean arrival dates, $m_{i, j, t}$ 's, in (1) are assumed to be conditionally independent (conditioned on a process model that accounts for spatial and temporal dependence) and thus, the off-diagonal elements of $\mathbf{D}_{j, t}$ 's are set to zero.

We define the Process Models as follows

$$
m_{i, j, t}=b_{0, j}+\mu_{i, j}+\mathbf{X}_{i, j, t}^{\prime} \mathbf{b}_{j}+\mathbf{U}_{i, j, t}^{\prime} \mathbf{a}_{j}, \quad \text { for } j=1,2 ; i=1, \ldots, n ; t=1, \ldots, T,
$$

where $\boldsymbol{\mu}_{j}=\left(\mu_{1, j}, \ldots, \mu_{n, j}\right)^{\prime}$ denotes the spatially-varying mean for the $j$ th species, $b_{0, j}$ is the "global mean", $\mathbf{b}_{j}=\left(b_{1, j}, \ldots, b_{K, j}\right)^{\prime}$ represent the vector of regression coefficients with elements for $K$ predictor variables, and $\mathbf{a}_{j}=\left(a_{1, j} \ldots, a_{C, j}\right)^{\prime}$ denote the vector of coefficients with elements for $C$ temporal trend parameters (linear, quadratic, cubic, etc.). $\mathbf{X}_{i, j, t}$ denotes the vector of predictor variables for the $i$ th grid cell, and $\mathbf{U}_{i, j, t}$ denotes the vector of temporal predictors (e.g., with all elements equal to $t, t^{2}, t^{3}$, etc.) for the ith grid cell. Note that in our case we only have 10 years of data with 
no strong evidence of temporal dependence in the data and thus, an autoregressive model for the temporal component of the model does not seem appropriate (e.g. Arab and Courter, 2015 use an AR(1) process to model temporal dependence). Our predictor variables include January-February temperature (JF-Temp), February-April precipitation (FA-Precip), WNAO, mean altitude (calculated based on the mean of altitude values for each cell), and sampling effort (i.e., the number of observers in each cell). All the predictor variables were standardized.

Additionally, we consider a process model for the measurement error of data. This is a critical component of our approach given that the data are obtained using Citizen Science programs in lack of a scientific sample design, and with varying sampling efforts over space and time. We extend the approach described in Yan (2007) and Reich and Hodges (2008) to model spatially-varying measurement error variances using a heteroskedastic Conditional Autoregressive (CAR) model. To this end, we model the "true" standard deviations for each cell, in each year, based on constant, spatial, and temporal components of variability, as well as predictor information:

$$
\log \left(\sigma_{i, j, t}\right)=u_{j}+\phi_{i, j}+v_{j, t}+\alpha_{j} x_{i, j, t}^{s}, \quad \text { for } j=1,2 ; i=1, \ldots, n ; t=1, \ldots, T,
$$

where $u_{j} \sim N\left(0, \sigma_{u, j}^{2}\right)$ denotes the log error standard deviation for species $j, \phi_{i, j}$ represents the change of log error standard deviation for the $i$ th grid cell compared to the average error standard deviation for species $j, v_{j, t} \sim N\left(0, \sigma_{v, j}^{2}\right)$ denotes the log error standard deviation for time $t$ for species $j, x_{i, j, t}^{s}$ denotes the predictor variable that predicts the magnitude of the error, and $\alpha_{j}$ denotes the corresponding regression coefficient for $x_{i, j, t}^{s}$. In general, we may consider several predictor variables, however, based on model selection results, we only consider sampling effort as a predictor variable for the error standard deviation.

We consider the spatial structure for the spatially-varying parameters $\boldsymbol{\mu}_{j}$, for $j=1,2$ based on CAR models (see, e.g., Cressie and Wikle, 2011 and Banerjee et al., 2014):

$$
\mu_{j, l} \mid \boldsymbol{\mu}_{j,-l}, \tau_{j, l}^{2} \sim N\left(\sum_{s \in N_{l}} c_{j, l s} \mu_{j, s}, \tau_{j, l}^{2}\right) .
$$

where $l, s=1, \ldots, n$, and $\boldsymbol{\mu}_{j,-l}$ denotes the vector of spatially-varying parameters for all grid cells except the lth grid cell. Also, $N_{l}$ is the set of neighboring sites for $l$, and $c_{j, l s}$ 's are weights defined such that $c_{j, l s}=1$ for $l \neq s, c_{j, q q}=0$ for $q=1, \ldots, n$, and $c_{j, l s} \tau_{j, l}^{2}=c_{j, s l} \tau_{j, s}^{2} \cdot \tau_{j, l}^{2}$ 's denote precision parameters (i.e., the inverse of variance components) and are commonly assumed to be the same and equal to $\tau_{j}^{2}$.

Alternatively, one may consider a bivariate intrinsic CAR (BICAR) model for the spatial structure of $\boldsymbol{\mu}_{1}$ and $\boldsymbol{\mu}_{2}$ (for details see Mardia, 1988; Carlin and Banerjee, 2003 and Gelfand and Vounatsou, 2003). This choice poses an assumption of dependence between spatial means for the two species. The choice of multivariate CAR models seems appropriate for analyzing spring arrival data for ecologically related species. However, we do not have strong scientific evidence supporting this assumption for the two species under study.

Similarly, we consider $\boldsymbol{\phi}_{j} \sim \operatorname{CAR}\left(\tau_{\phi, j}^{2}\right)$ where $\boldsymbol{\phi}_{j}=\left(\phi_{1, j}, \ldots, \phi_{n, j}\right)^{\prime}$ is the vector of spatially-varying components for the log measurement error standard deviation, and $\tau_{\phi, j}^{2}$ represents the precision parameter of the CAR model (defined similarly as in Eq. (4)).

\subsection{Model implementation and inference}

Inference is conducted in a Bayesian framework using Markov chain Monte Carlo (MCMC; e.g., see Robert and Casella, 2004). We define the following relatively non-informative prior distributions (i.e., distributions with small mean and relatively large variance) for the unknown parameters (also called the Parameter Models in the hierarchical framework) for species $j=1,2$,

$$
\begin{aligned}
b_{k, j} & \sim N\left(\mu=0, \sigma^{2}=100\right), \quad k=0,1, \ldots, K, \\
a_{d, j} & \sim N\left(\mu=0, \sigma^{2}=100\right), \quad d=1, \ldots, C, \\
\sigma_{\epsilon, j}^{2} & \sim \text { InvGamma }(\text { mean }=1, \text { var }=100) .
\end{aligned}
$$


We also define the following prior distributions for the precision parameters of the CAR priors for both models (i.e., hyperparameters for the CAR priors)

$$
\begin{aligned}
\tau_{j}^{2} & \sim \operatorname{Gamma}(\text { mean }=1, \operatorname{var}=100), \quad j=1,2, \\
\tau_{\phi, j}^{2} & \sim \operatorname{Gamma}(\text { mean }=1, \operatorname{var}=100), \quad j=1,2 .
\end{aligned}
$$

For the remaining unknown parameters of the measurement error process model, we considered the following relatively non-informative prior distributions for species $j=1,2$,

$$
\begin{aligned}
\alpha_{j} & \sim N\left(\mu=0, \sigma^{2}=100\right), \\
\sigma_{u, j}^{2} & \sim \operatorname{InvGamma}(\text { mean }=1, \operatorname{var}=100), \\
\sigma_{v, j}^{2} & \sim \operatorname{InvGamma}(\text { mean }=1, \operatorname{var}=100) .
\end{aligned}
$$

The model is implemented using OpenBUGS (http://www.openbugs.net). The algorithm was implemented for 30,000 iterations. We discarded the first 5000 iteration for "burn-in" and based our inference on the remaining 25,000 iterations. The MCMC algorithm achieved convergence rapidly (within the first 1000 iterations). Convergence was assessed using visual inspection of the MCMC chains and their autocorrelations. We did not experience any sensitivity of the results to the variances of the prior densities. In order to assess the difference between the spatially-varying means between the two species, at each iteration of the MCMC, we compute the difference between the spatiallyvarying means, yielding a posterior distribution for the spatial mean differences $\left(\boldsymbol{\mu}_{1}-\boldsymbol{\mu}_{2}\right)$. We similarly obtain posterior distributions for the difference of the constant means for the two species $\left(b_{0,1}-b_{0,2}\right)$, and the difference of spatially-varying components of error standard deviations $\left(e^{\phi_{1}}-e^{\phi_{2}}\right)$. The data and code are available upon request from the corresponding author.

\section{Results}

We considered several competing models with different spatial and temporal structures. We conducted all the comparisons based on the deviance information criterion (DIC; Spiegelhalter et al., 2002). For example, different temporal trends with linear, quadratic, and cubic trends were compared. We considered the range of altitudes in each cell as an alternative to the mean of altitudes, however, the models with the mean of altitudes outperformed the models with the range of altitudes. Also, we considered models with spatially-varying coefficients for the temporal trend components in Eq. (2) to account for potential space-time interactions, and different sets of potential predictor variables for the measurement error process model. For brevity, the details of the model comparisons are not presented. The final model discussed below includes a third-order polynomial for the temporal trend (linear, quadratic and cubic terms) for the Purple Martin data, and a second-order polynomial for the temporal trend (linear and quadratic terms) for the Ruby-throated Hummingbirds' with no space-time interaction for either of the two models, and uses sampling effort as the only predictor variable for the measurement error process model.

The posterior mean first arrival date of Purple Martins and Ruby-throated hummingbirds in our study was March 14 (i.e., the 73rd day of the year; Table 1) and April 14 (i.e., the 104th day of the year; Table 1), respectively. Differences were noted in how spatial and climate variables impacted migration dates; for example, WNAO was not statistically significant for predicting first arrival dates of Purple Martins, however, it was positively correlated with arrival dates of Ruby-throated Hummingbirds (Table 1). Higher winter temperatures were associated with earlier migration dates for hummingbirds, but did not appear to impact first arrival dates of martins (Table 1). For hummingbirds, later arrival dates were reported at higher altitudes (Table 1). The temporal trends (linear, quadratic, and cubic) were only significant for hummingbirds (Table 1). On average, martins arrived approximately 31 days earlier than hummingbirds (Table 2), although martin arrivals in relation to the overall mean difference were most pronounced at lower latitudes (Fig. 1) with lower variability in the central to higher latitudes (Fig. 2). The average differences in measurement error standard deviations were more pronounced in the central latitudes (Fig. 3) with higher variability in the lower and higher latitudes (Fig. 4). Our results did not show any significant effect of sampling effort on log measurement 
Table 1

Posterior results for the model parameters for both species Purple Martins (PUMA) and Ruby-throated Hummingbirds (RUTH).

\begin{tabular}{lllll}
\hline Species & Parameter & Posterior mean & Posterior St. Dev. & 95\% credible interval \\
\hline PUMA & & & & \\
& Intercept & 72.73 & 0.344 & $(72.06,73.41)$ \\
& WNAO & 0.035 & 0.31 & $(-0.57,0.64)$ \\
& JF-Temp & -0.042 & 0.54 & $(-1.079,1.029)$ \\
& Mean altitude & 1.563 & 0.78 & $(0.008,3.06)$ \\
& FA-Precip & -0.1624 & 0.23 & $(-0.621,0.282)$ \\
& Sampling effort & 1.16 & 0.434 & $(0.33,2.02)$ \\
& Temporal (linear) & -1.001 & 0.584 & $(0.335,1.609)$ \\
& Temporal (quadratic) & 0.972 & 0.326 & $(0.453,1.802)$ \\
& Temporal (cubic) & 1.116 & 0.3402 & \\
& & & & $(103.1,104.1)$ \\
& RUTH & 103.6 & 0.251 & $(0.343,1.122)$ \\
& Intercept & 0.738 & 0.1998 & $(-3.54,-1.88)$ \\
& WNAO & -2.726 & 0.426 & $(0.56,2.561)$ \\
& JF-Temp & 1.507 & 0.509 & $(-0.558,-0.017)$ \\
& Mean altitude & -0.287 & 0.138 & $(-0.354,0.595)$ \\
& FA-Precip & 0.1162 & 0.241 & $(-0.644,0.25)$ \\
& Sampling effort & -0.1993 & 0.227 & $(-0.0703,0.7915)$ \\
& Temporal (linear) & 0.3575 & 0.2184 & \\
& Temporal (quadratic) & 0.728 & \\
\end{tabular}

Table 2

Posterior results for the difference in global means $\left(b_{0,1}-b_{0,2}\right)$ for PUMA and RUTH.

\begin{tabular}{llll}
\hline Parameter & Posterior mean & Posterior St. Dev. & 95\% credible interval \\
\hline Difference (PUMA-RUTH) & -30.9 & 0.4806 & $(-31.84,-29.95)$ \\
\hline
\end{tabular}

error standard deviation of martins after accounting for spatial and temporal variability components (Table 3). However, sampling effort was negatively related with log measurement error standard deviation of hummingbirds (Table 3). Additionally, Table 3 shows the results for constant and temporal variability components of the log measurement error model.

\section{Conclusion and discussion}

Our results indicate that spatial and climate variables affect first arrival dates of Ruby-throated Hummingbirds and Purple Martins both similarly and differently (Table 1). Arrival dates of Purple Martin were not associated with WNAO. Later arrival dates for hummingbirds were associated with higher WNAO values (Visbeck et al., 2001) which is somewhat unexpected (although, see Hubálek and Čapek, 2008) and may reflect their more specialized food preferences during migration or the relatively short temporal scale of our study (i.e., 2001-2010; Stervander et al., 2005). Warmer January and February temperatures, and higher precipitation levels for February through April were associated with earlier arrivals of hummingbirds in our study (Table 1) and suggest that warming winter temperatures and higher precipitation levels may lead to migratory advancements over time. Both martins and hummingbirds arrived later at higher and presumably cooler altitudes (Table 1) which is consistent with the hypothesis that first arrival dates are, at least partially, dependent on temperature.

Sampling effort (based on number of observations for each cell) were only significant for Purple Martins. This means earlier arrival dates were associated with lower sampling effort which could indicate potential inaccuracy of the earlier arrival reports. Sampling effort was not significant for hummingbirds and thus, these reports may be considered as more reliable in some sense.

A key benefit of our approach is the ability to compare migratory changes of two (or more) species across space (Table 2; Figs. 1 and 2). Although Purple Martins arrived 30.9 days earlier than hummingbirds, this difference was most pronounced in southern latitudes (Fig. 1). This suggests that martins arrived much earlier in southern portion of our study region, but migrated northward at 
Table 3

Posterior results for the measurement error model parameters for PUMA and RUTH.

\begin{tabular}{cllll}
\hline Species & Parameter & Posterior mean & Posterior St. Dev. & 95\% credible interval \\
\hline PUMA & & & & \\
& Sampling effort & -0.09443 & 0.05923 & $(-0.2084,0.01631)$ \\
& $u_{1}$ & 1.014 & 0.09672 & $(0.8275,1.216)$ \\
& $v_{1,1}$ & -0.1199 & 0.1604 & $(-0.4229,0.1919)$ \\
& $v_{1,2}$ & -0.1156 & 0.1618 & $(-0.4532,0.1952)$ \\
& $v_{1,3}$ & -.00033 & 0.1598 & $(-0.3247,0.3078)$ \\
& $v_{1,4}$ & -0.2148 & 0.1607 & $(-0.5549,0.0931)$ \\
& $v_{1,5}$ & -0.0115 & 0.1617 & $(-0.327,0.2921)$ \\
& $v_{1,6}$ & -0.0106 & 0.1586 & $(-0.3244,0.3182)$ \\
& $v_{1,7}$ & -0.0205 & 0.1573 & $(-0.3368,0.3003)$ \\
& $v_{1,8}$ & 0.1666 & 0.155 & $(-0.1405,0.492)$ \\
& $v_{1,9}$ & -0.1223 & 0.1649 & $(-0.4502,0.1996)$ \\
& $v_{1,10}$ & 0.415 & 0.1592 & \\
& & & & $(-0.37231,0.7599)$ \\
& Sampling effort & -0.2378 & 0.0689 & $(0.4911,0.91)$ \\
& $u_{2}$ & 0.7099 & 0.1042 & $(-0.1523,0.4805)$ \\
& $v_{2,1}$ & 0.1541 & 0.1601 & $(-0.3537,0.2878)$ \\
& $v_{2,2}$ & -0.0339 & 0.1627 & $(-0.2274,0.4136)$ \\
& $v_{2,3}$ & 0.08604 & 0.1631 & $(-0.5695,0.119)$ \\
& $v_{2,4}$ & -0.2143 & 0.1742 & $(-0.4882,0.1806)$ \\
& $v_{2,5}$ & -0.1549 & 0.1687 & $(-0.339,0.3149)$ \\
& $v_{2,6}$ & -0.01747 & 0.1684 & $(-0.2165,0.4625)$ \\
& $v_{2,7}$ & 0.1137 & 0.1696 & $(-0.3824,0.2921)$ \\
& $v_{2,8}$ & -0.04379 & 0.1706 & $(-0.05178,0.6501)$ \\
& $v_{2,9}$ & -0.1195 & 0.1858 & \\
& $v_{2,10}$ & 0.2768 & 0.1743 & \\
\hline
\end{tabular}

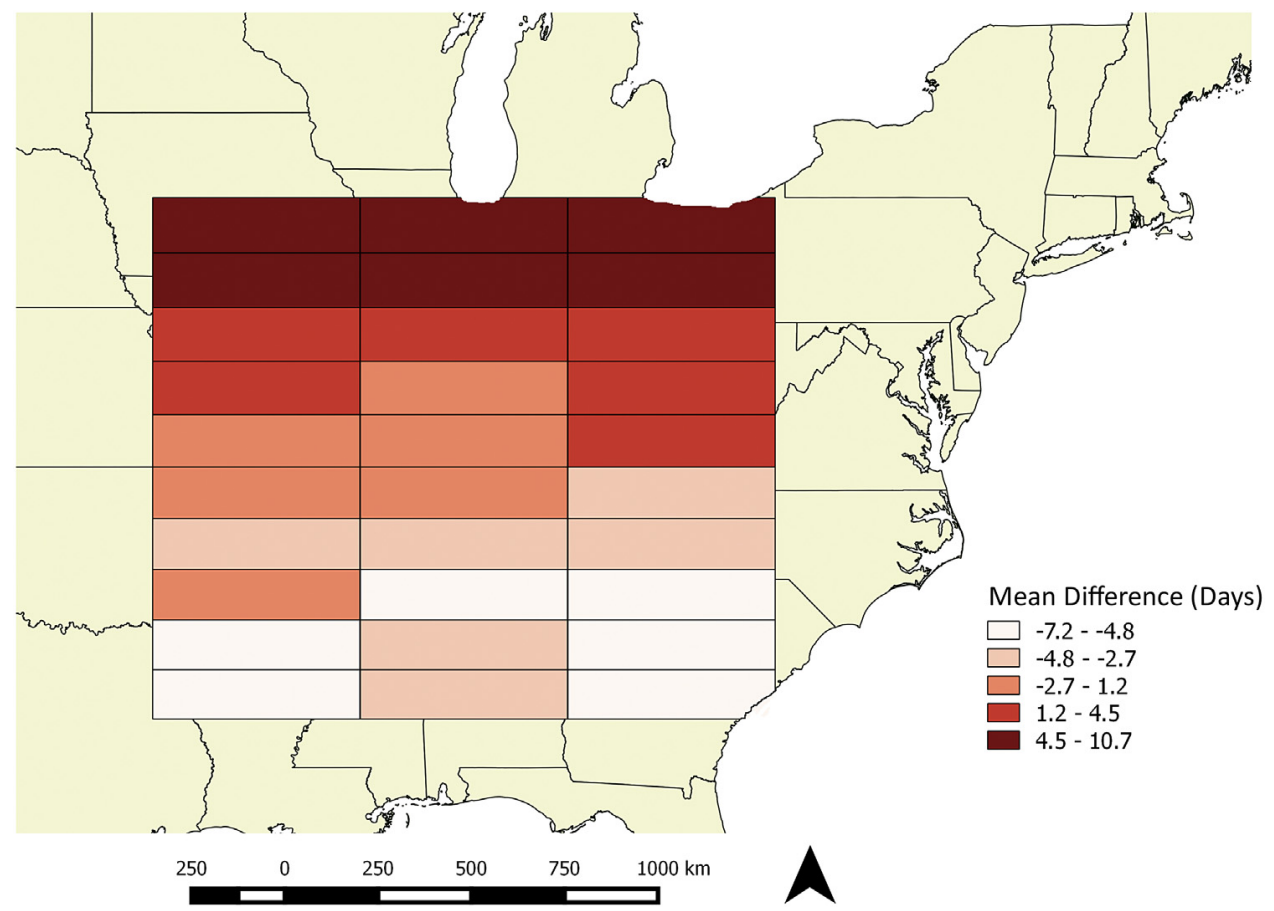

Fig. 1. Posterior means of the difference between the spatially-varying means of Purple Martins and Ruby-throated Hummingbirds. 


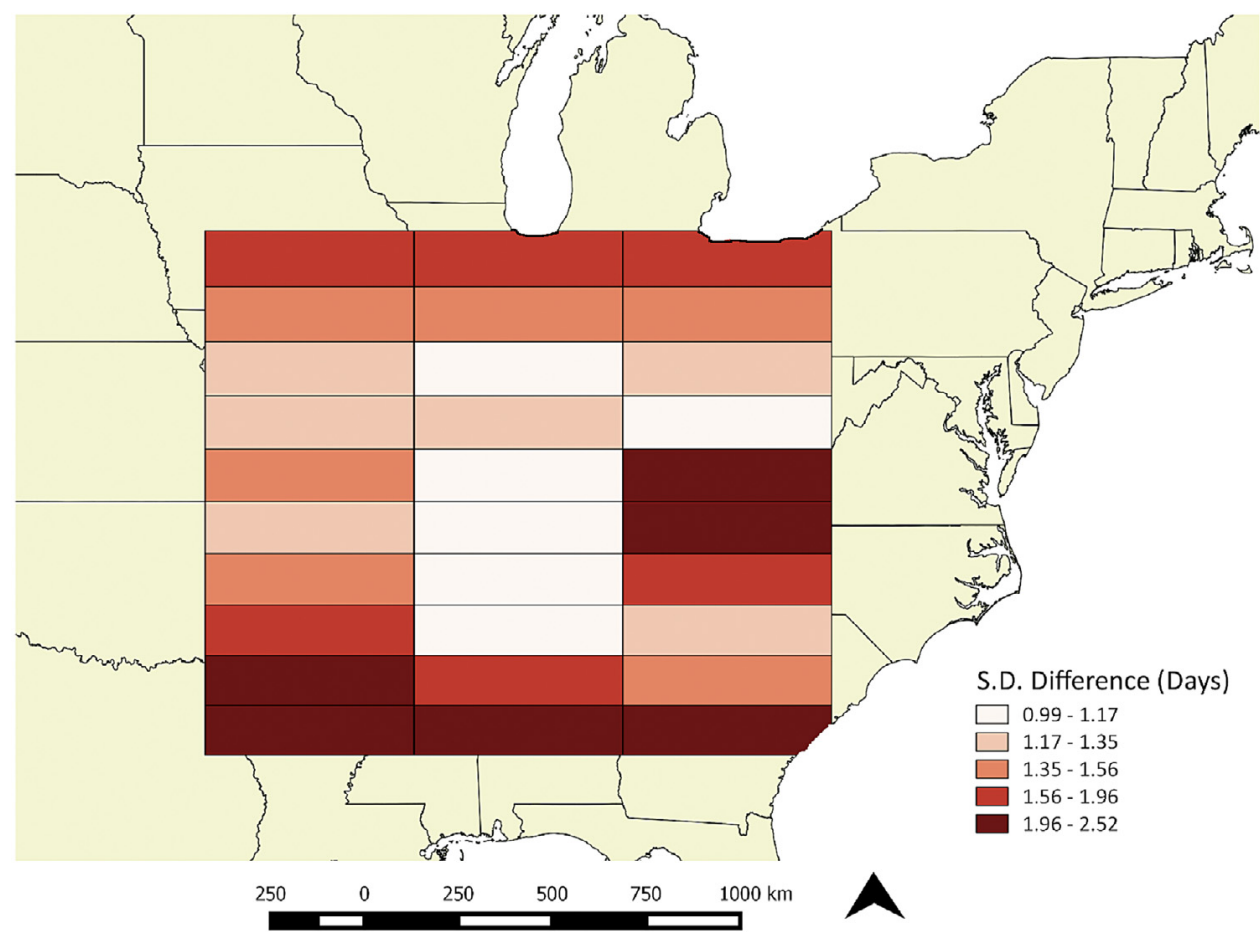

Fig. 2. Posterior standard deviations of the difference between the spatially-varying means of Purple Martins and Rubythroated Hummingbirds.

slower rates than hummingbirds. We propose at least four possible explanations for this difference. First, early arriving martins in this study are likely to be male "scouts" that may arrive several weeks before other martins and spend additional time investigating suitable breeding areas (Tarof and Brown, 2013; hummingbird males also arrive before females but typically only about 10 days; Robinson et al., 1996). The breeding range of hummingbirds also extends well into many Canadian provinces whereas the breeding range of martins is primarily within the United States, meaning that "slower migration" in martins may actually be a result of more birds stopping to nest at suitable locations in more southerly latitudes. Thirdly, a number of manufactured birdhouses available for Purple Martins to shelter in may slow their northward advancement during the early migration period. Finally, Purple Martins are aerial insectivores and insect development and life stage is typically advanced in response to warming winter temperatures (Robinet and Roques, 2010). Hummingbirds, on the other hand, are primarily nectarivores and recent evidence suggests that a failure to meet winter chilling requirements may actually delay budbreak in some plants (Cook et al., 2012) in more southerly latitudes (Zhang et al., 2007), and could potentially impact the migratory timing of species such as hummingbirds that depend on these plants for food (Courter et al., 2013a). For our analysis, we chose to compare migration in two long-distance migrants which may help pinpoint some of the more subtle ecological and life history reasons for the differences that we observed in migration patterns. As data to elucidate reasons for migratory change become increasingly available, we suggest that researchers carefully consider the feeding ecologies and life history traits of candidate species (or ecological guilds) for future comparisons.

Another important element of our modeling approach is to model measurement error through a spatio-temporal log error standard deviation process. Our results (Table 3 ) indicate that higher sampling effort for hummingbirds was associated with lower log measurement error standard deviation. However, sampling effort was not significantly important for Purple Martins. In these models, constant, spatial, and temporal components of the variability for the log error standard 


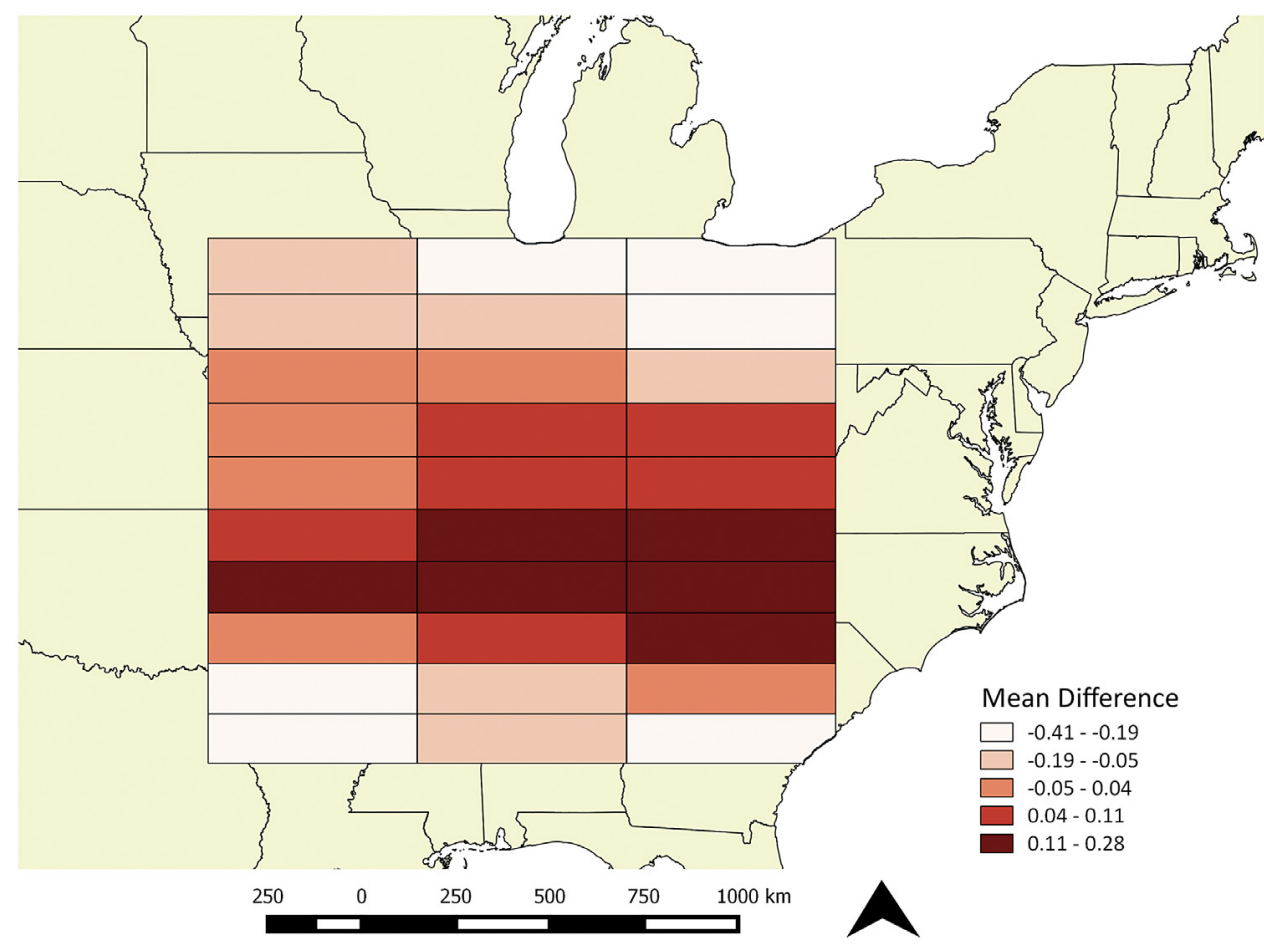

Fig. 3. Posterior means of the difference between the spatially-varying standard deviations of log measurement models for Purple Martins and Ruby-throated Hummingbirds $\left(e^{\phi_{1}}-e^{\phi_{2}}\right)$.

deviation were considered (Table 3, Figs. 3 and 4). The average differences between the measurement error standard deviations between the two species were pronounced more in the central latitudes (Fig. 3), with higher uncertainty in the lower and higher latitudes (Fig. 4).

Our analysis also identifies several areas that require further development of statistical methodology. First, our choice of the grid system to aggregate data was limited by data availability (due to lack of a consistent design, data collected in some areas and/or years are very sparse). We believe that ideally one should use careful methodology to form an "optimal" grid over the study domain based on minimizing aggregation error (e.g., Bradley et al., 2015). Next, data collected through Citizen Science programs are prone to many sources of bias (e.g., see discussion in Courter et al., 2013b). Provided additional statistical information is collected regarding the observers and conditions of data collections, methods for assessing or estimating bias in Citizen Science data may be developed. Moreover, first arrival dates are the dates that species were first reported by an observer in an area and do not necessarily indicate the actual date that the species arrived to the area (i.e. detection may be imperfect). Here, we limit our interpretation of the results to the first observed arrival dates. However, if one is interested in modeling the actual arrival dates of species, one should use statistical methods that may address the censored/truncated nature of these data. And, finally, the comparison of spatially-varying means may be adjusted using multiple comparison procedures, however, most of the existing multiple comparison methods are only suitable for independent cases and extensions to spatial data are subjects of ongoing research (see Sun et al., 2015 and references therein).

Here, we demonstrate a technique for comparing migratory changes in two commonly reported bird species in eastern North America during a 10-year time span. Our proposed method may be adjusted and extended to include more complex settings (e.g., potential non-linear effects of predictor data, and temporal dependence, among others). Additionally, our approach considers modeling measurement error based on modeling the error standard deviation using constant, spatial, and temporal components, as well as potential predictor information to address the issue of varying 


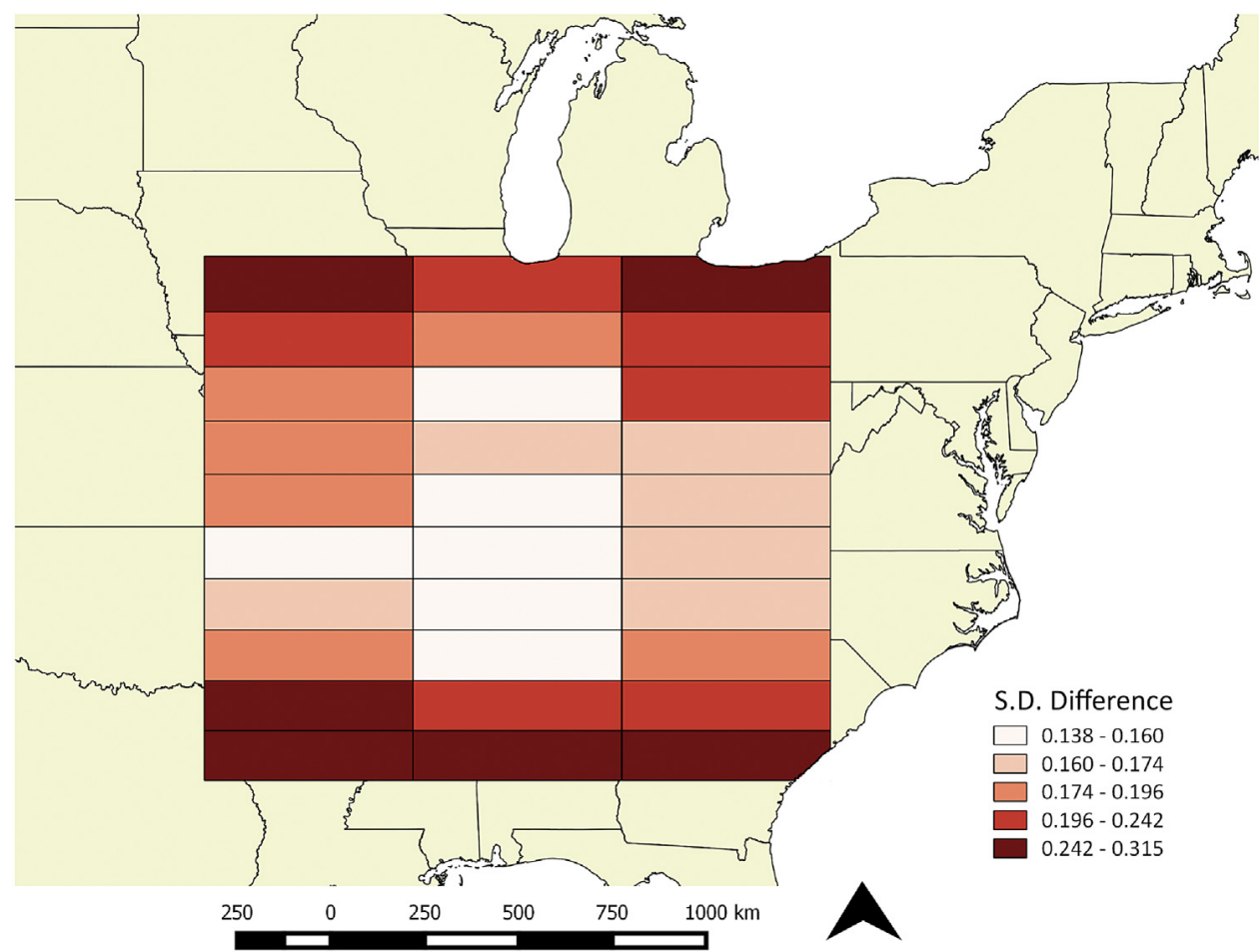

Fig. 4. Posterior standard deviations of the difference between the spatially-varying standard deviations of log measurement models for Purple Martins and Ruby-throated Hummingbirds $\left(e^{\phi_{1}}-e^{\phi_{2}}\right)$.

sampling effort over time and space which is a common issue in Citizen Science data. Furthermore, our model may be generalized to compare spatial patterns of first arrival data for multiple species. Our hope is that our results and spatio-temporal methodology provide direction for others to analyze similar Citizen Science datasets in ways that provide us with an improved ecological understanding of our changing environment.

\section{Acknowledgments}

We thank L. Chambers from hummingbirds.net, E. Howard from Journey North, with funding from the Annenberg Foundation, and the Purple Martin Conservation Association for collecting and compiling thousands of first-arrival reports. We are also grateful to the countless contributors from Journey North, hummingbirds.net, and the Purple Martin Conservation Association for a decade of careful observation which made a study of this magnitude possible. The authors would like to thank Alfred Stein and Denis Allard for the invitation to submit to the special issue. We would also like to thank the Guest Editor and anonymous reviewers for carefully reading the manuscript. Their helpful and critical comments and suggestions on our earlier drafts helped us substantially improve the manuscript.

\section{Appendix A. Supplementary data}

Supplementary material related to this article can be found online at http://dx.doi.org/10.1016/j. spasta.2016.06.006. 


\section{References}

Arab, A., Courter, J.R., 2015. Spatio-temporal trend analysis of spring arrival data for migratory birds. Comm. Statist. Simulation Comput. 44 (10), 2535-2547.

Arab, A., Hooten, M.B., Wikle, C.K., 2008. Hierarchical spatial models. In: Shekhar, S., Xiong, H. (Eds.), Encyclopedia of Geographical Information Science. Springer, New York, pp. 425-431.

Banerjee, S., Carlin, B.P., Gelfand, A.E., 2014. Hierarchical Modeling and Analysis for Spatial Data. CRC Press.

Berliner, L.M., 1996. Hierarchical Bayesian time series models. In: Hanson, K., Silver, R. (Eds.), Maximum Entropy and Bayesian Methods. Kluwer Academic Publishers, Dordrecht, pp. 15-22.

Bradley, J.R., Wikle, C.K., Holan, S.H., 2015. Regionalization of multiscale spatial processes using a criterion for spatial aggregation error. arXiv:1502.01974.

Butler, C.J., 2003. The disproportionate effect of global warming on the arrival dates of short-distance migratory birds in North America. Ibis 145 (3), 484-495.

Carlin, B.P., Banerjee, S., 2003. Hierarchical multivariate CAR models for spatio-temporally correlated survival data (with discussion). In: Bernardo, J.M., Bayarri, M.J., Berger, J.O., Dawid, A.P., Heckerman, D., Smith, A.F.M., West, M. (Eds.), Bayesian Statistics 7. Oxford University Press, Oxford, pp. 44-63.

Clark, J.S., 2005. Why environmental scientists are becoming Bayesians. Ecol. Lett. 8, 2-14.

Cook, B.I., Wolkovich, E.M., Parmesan, C., 2012. Divergent responses to spring and winter warming drive community level flowering trends. Proc. Natl. Acad. Sci. 109 (23), 9000-9005.

Courter, J.R., Johnson, R.J., Bridges, W.C., Hubbard, K.G., 2013a. Assessing migration of Ruby-throated Hummingbirds (Archilochus colubris) at broad spatial and temporal scales. Auk 130 (1), 107-117.

Courter, J.R., Johnson, R.J., Stuyck, C.M., Lang, B.A., Kaiser, E.W., 2013b. Weekend bias in citizen science data reporting: implications for phenology studies. Int. J. Biometeorol. 57 (5), 715-720.

Cressie, N., Wikle, C.K., 2011. Statistics for Spatio-Temporal Data. Wiley, New York, NY.

Gelfand, A.E., Vounatsou, P., 2003. Proper multivariate conditional autoregressive models for spatial data analysis. Biostatistics $4,11-25$.

Gordo, O., Barriocanal, C., Robson, D., 2011. Ecological impacts of the North Atlantic oscillation (NAO) in Mediterranean ecosystems. In: Hydrological, Socioeconomic and Ecological Impacts of the North Atlantic Oscillation in the Mediterranean Region. Springer Netherlands, pp. 153-170.

Hostetler, J.A., Sillett, T.S., Marra, P.P., 2015. Full-annual-cycle population models for migratory birds. Auk 132 (2), $433-449$.

Hubálek, Z., Čapek, M., 2008. Migration distance and the effect of North Atlantic oscillation on the spring arrival of birds in Central Europe. Folia Zool. 57 (3), 212-220.

Hurlbert, A.H., Liang, Z., 2012. Spatiotemporal variation in avian migration phenology: Citizen science reveals effects of climate change. PLoS One 7, e31662.

Knudsen, E., Lindén, A., Both, C., Jonzén, N., Pulido, F., Saino, N., Sutherland, W.J., Bach, L.A., Coppack, T., Ergon, T., Gienapp, P., 2011. Challenging claims in the study of migratory birds and climate change. Biol. Rev. 86 (4), 928-946.

Laughlin, A.J., Taylor, C.M., Bradley, D.W., Leclair, D., Clark, R.C., Dawson, R.D., Dunn, P.O., Horn, A., Leonard, M., Sheldon, D.R., Shutler, D., 2013. Integrating information from geolocators, weather radar, and citizen science to uncover a key stopover area of an aerial insectivore. Auk 130 (2), 230-239.

Ledneva, A., Miller-Rushing, A.J., Primack, R.B., Imbres, C., 2004. Climate change as reflected in a naturalist's diary, Middleborough, Massachusetts. Wilson Bull. 116 (3), 224-231.

Mardia, K.V., 1988. Multi-dimensional multivariate Gaussian Markov random fields with application to image processing. J. Multivariate Anal. 24, 265-284.

Matthews, S.N., Iverson, L.R., Prasad, A.M., Peters, M.P., 2011. Changes in potential habitat of 147 North American breeding bird species in response to redistribution of trees and climate following predicted climate change. Ecography 34 (6), $933-945$.

McKinney, A.M., CaraDonna, P.J., Inouye, D.W., Barr, B., Bertelsen, C.D., Waser, N.M., 2012. Asynchronous changes in phenology of migrating Broad-tailed Hummingbirds and their early-season nectar resources. Ecology 93 (9), 1987-1993.

Møller, A.P., Fiedler, W., Berthold, P., 2010. Effects of Climate Change on Birds. Oxford University Press.

Parmesan, C., Yohe, G., 2003. A globally coherent fingerprint of climate change impacts across natural systems. Nature 421 (6918), 37-42.

Primack, R.B., Ibáñez, I., Higuchi, H., Lee, S.D., Miller-Rushing, A.J., Wilson, A.M., Silander, J.A., 2009. Spatial and interspecific variability in phenological responses to warming temperatures. Biol. Cons. 142 (11), 2569-2577.

Reich, B.J., Hodges, J.S., 2008. Modeling longitudinal spatial periodontal data: A spatially adaptive model with tools for specifying priors and checking fit. Biometrics 64 (3), 790-799.

Robert, C.P., Casella, G., 2004. Monte Carlo Statistical Methods, second ed. Springer-Verlag, New York.

Robinet, C., Roques, A., 2010. Direct impacts of recent climate warming on insect populations. Integr. Zool. 5 (2), $132-142$.

Robinson, T.R., Sargent, R.R., Sargent, M.B., 1996. Ruby-throated Hummingbird (Archilochus colubris). In: Poole, A. (Ed.), Birds of North America Online. Cornell Lab of Ornithology, Ithaca, New York, Available at http://bna.birds.cornell.edu/bna/species/ 204.

Spiegelhalter, D.J., Best, N.G., Carlin, B.P., Van der Linde, A., 2002. Bayesian measures of model complexity and fit (with discussion). J. R. Stat. Soc. Ser. B Stat. Methodol. 64, 583-616.

Stervander, M., Lindström, Å., Jonzén, N., Andersson, A., 2005. Timing of spring migration in birds: long-term trends, North Atlantic oscillation and the significance of different migration routes. J. Avian Biol. 36 (3), 210-221.

Studds, C.E., Marra, P.P., 2011. Rainfall-induced changes in food availability modify the spring departure programme of a migratory bird. Proc. R. Soc. Lond. B Biol. Sci. p.rspb20110332.

Sullivan, B.L., Aycrigg, J.L., Barry, J.H., Bonney, R.E., Bruns, N., Cooper, C.B., Damoulas, T., Dhondt, A.A., Dietterich, T., Farnsworth, A., Fink, D., 2014. The eBird enterprise: an integrated approach to development and application of citizen science. Biol. Cons. 169, 31-40.

Sun, W., Reich, B.J., Tony Cai, T., Guindani, M., Schwartzman, A., 2015. False discovery control in large-scale spatial multiple testing. J. R. Stat. Soc. Ser. B Stat. Methodol. 77 (1), 59-83. 
Swanson, D.L., Palmer, J.S., 2009. Spring migration phenology of birds in the Northern Prairie region is correlated with local climate change. J. Field Ornithol. 80 (4), 351-363.

Tarof, S., Brown, C.R., 2013. Purple martin (Progne subis). In: Poole, A. (Ed.), The Birds of North America Online. Cornell Lab of Ornithology, Ithaca, Retrieved from the Birds of North America Online: http://bna.birds.cornell.edu/bna/species/287doi: 10. 2173/bna.287.

Visbeck, M.H., Hurrell, J.W., Polvani, L., Cullen, H.M., 2001. The North Atlantic oscillation: past, present, and future. Proc. Natl. Acad. Sci. 98 (23), 12876-12877.

Wikle, C.K., 2003. Hierarchical models in environmental science. Internat. Statist. Rev. 71, 181-199.

Yan, J., 2007. Spatial stochastic volatility for lattice data. J. Agric. Biol. Environ. Stat. 12 (1), 25-40.

Zelt, J., Courter, J., Arab, A., Droege, S., 2012. Reviving a legacy citizen science project to illuminate shifting migratory bird patterns. Int. J. Zool. http://dx.doi.org/10.1155/2012/710710.

Zhang, X., Tarpley, D., Sullivan, J.T., 2007. Diverse responses of vegetation phenology to a warming climate. Geophys. Res. Lett. 34 (19) 
Supplementary Material: “Exploratory data analysis for Purple Martins and Ruby-Throated Hummingbirds data and the predictor variables"

\section{Purple Martins (PUMA)}

Purple Martins data show a strong spatial structure which is mainly due to the northbound migration process of Purple Martins. The latitudinal structure is strongly evident, however, there is some evidence of longitudinal structure too. The side-by-side boxplots below show all the data (over 10 years of 2001-2010) for each spatial grid cell. Cells are numbered 1-30 with 1,2, and 3 as the lowest latitudinal portions of the grid.

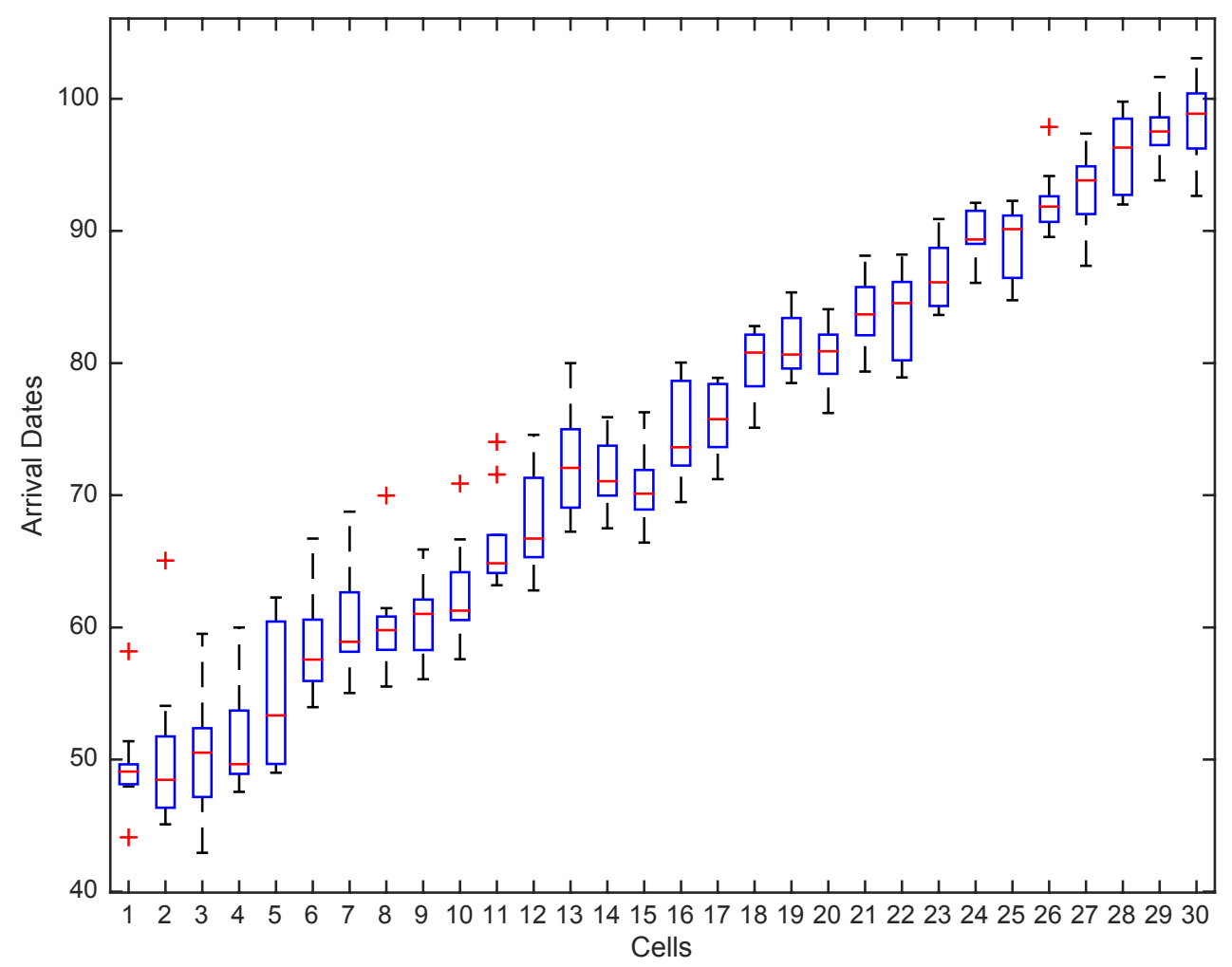


The temporal trends for each of the grid cells shows non-linear behavior. For brevity only odd-numbered cells are shown below. Each plot shows the mean of observations over the period 2001-2010 for a grid cell.
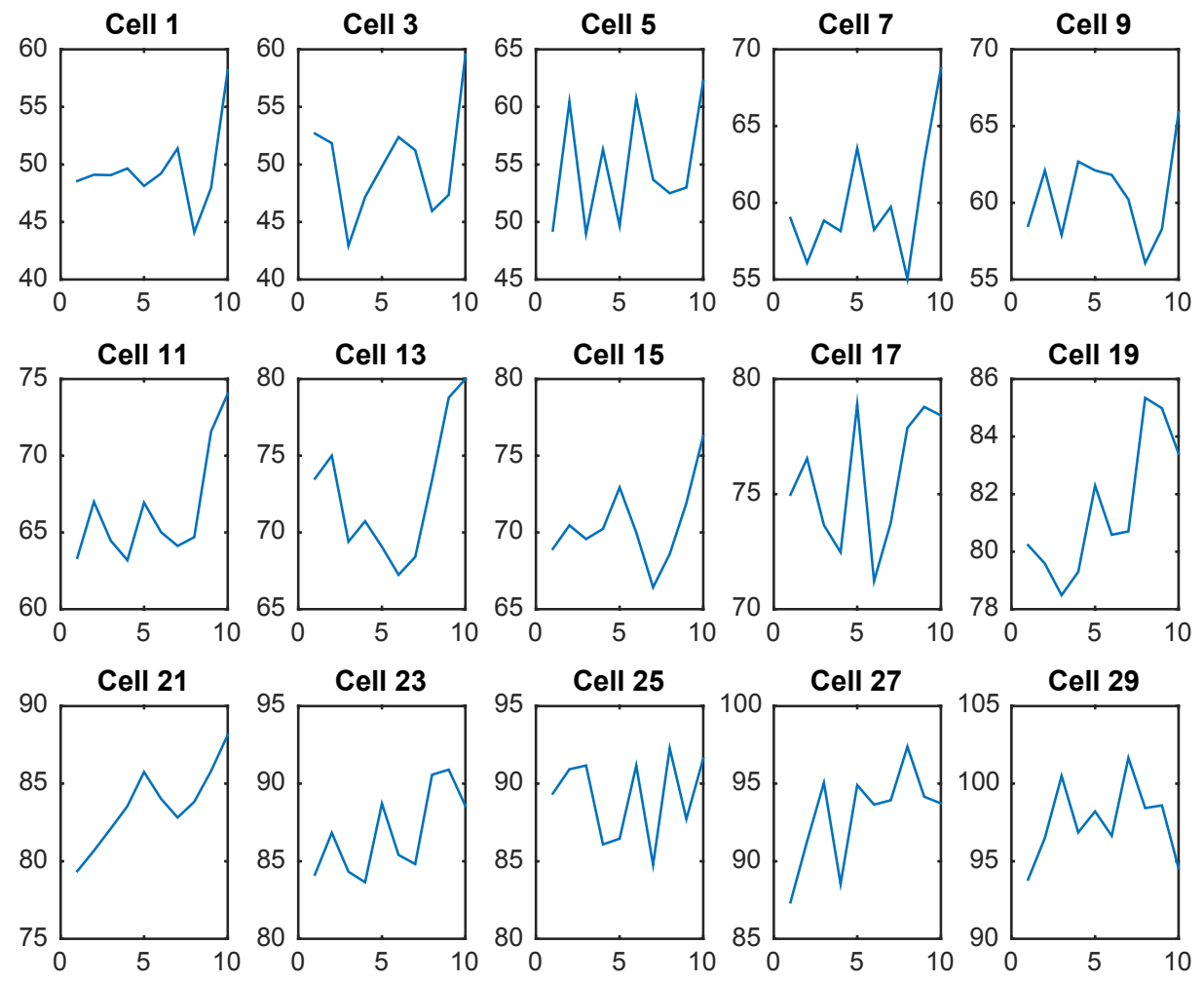
Plot of Jan-Feb Temperature versus Purple Martins Arrival Data:

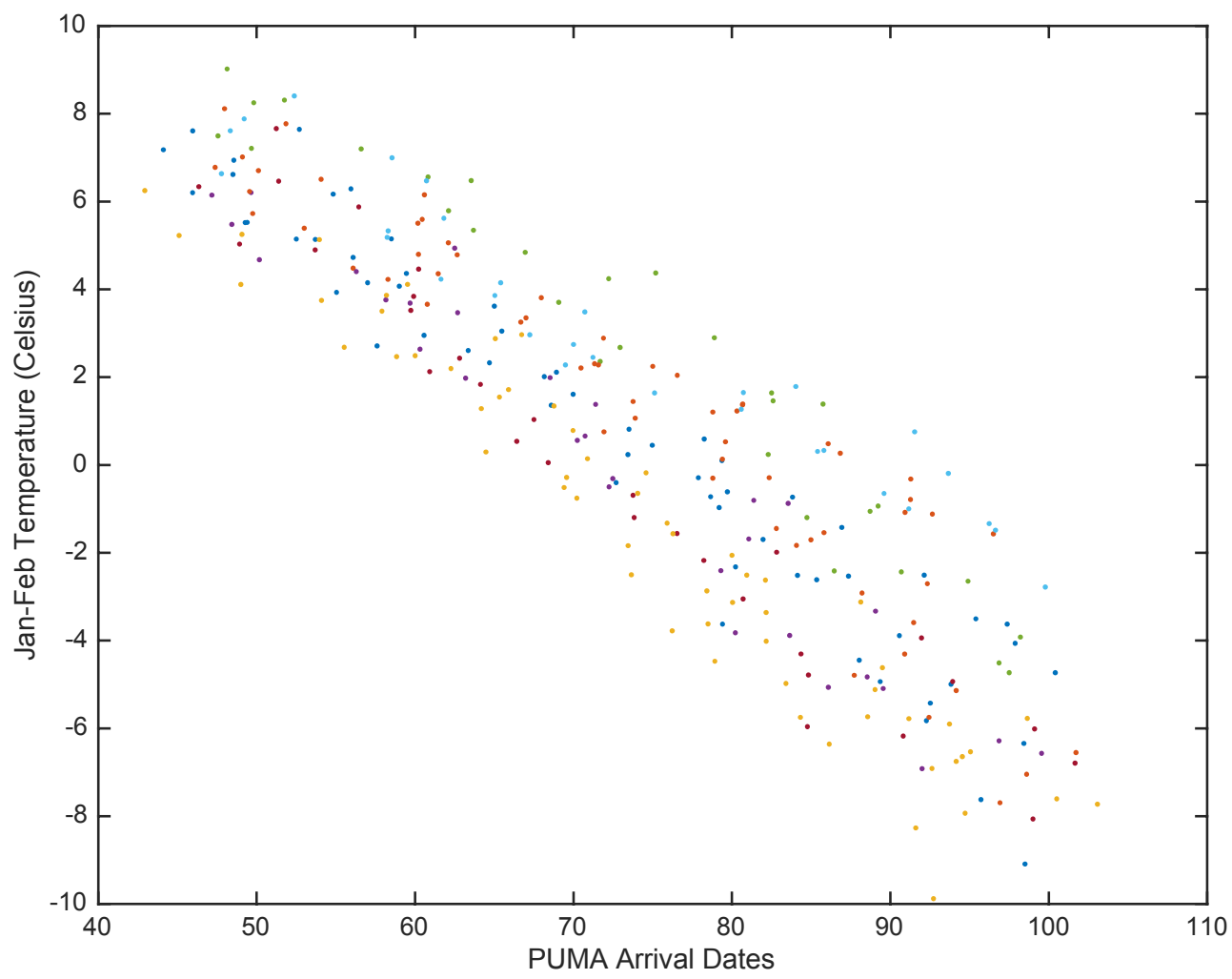


Plot of Sampling Effort versus Purple Martins Arrival Data:

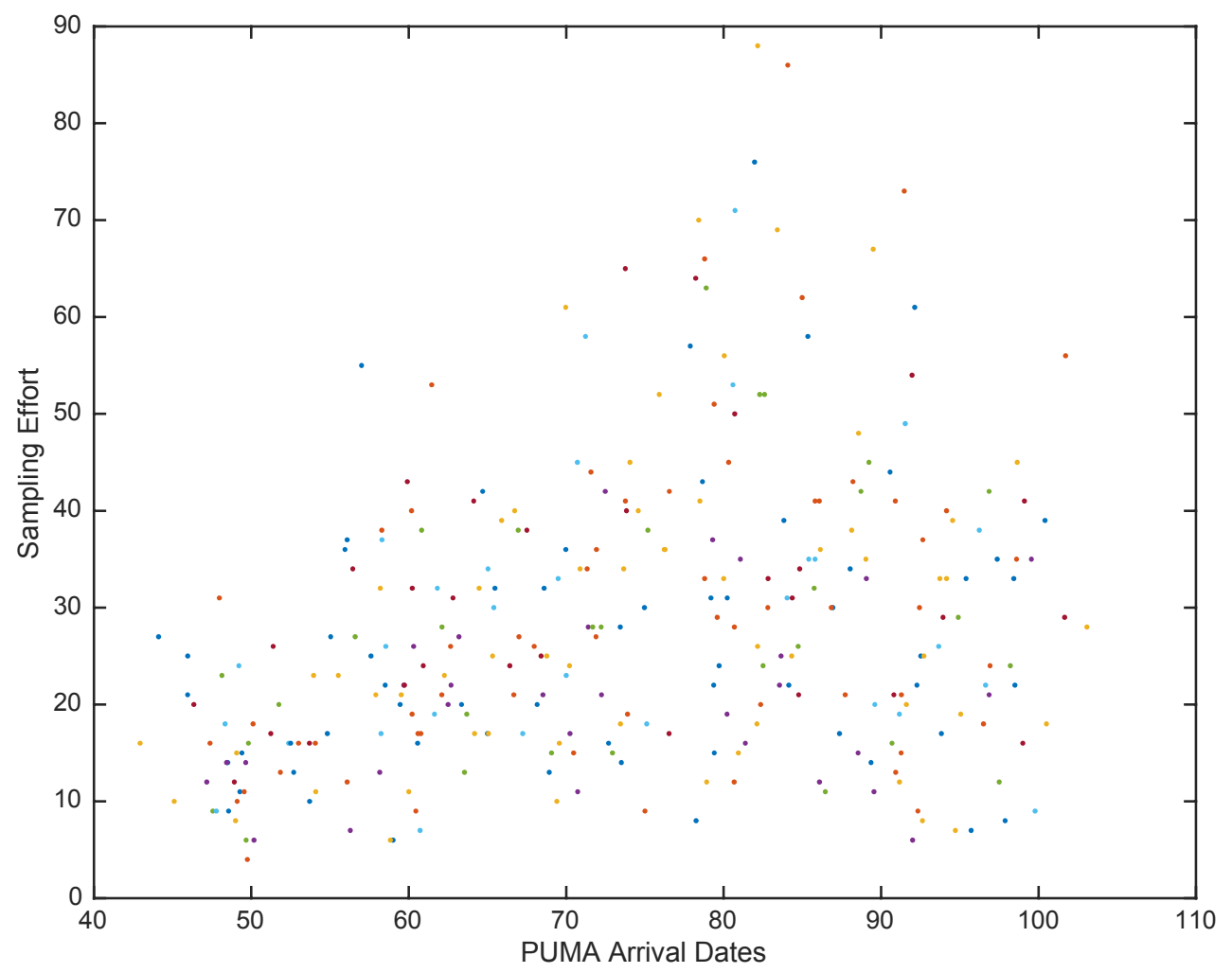


Plot of Mean Altitude versus Purple Martins Arrival Data:

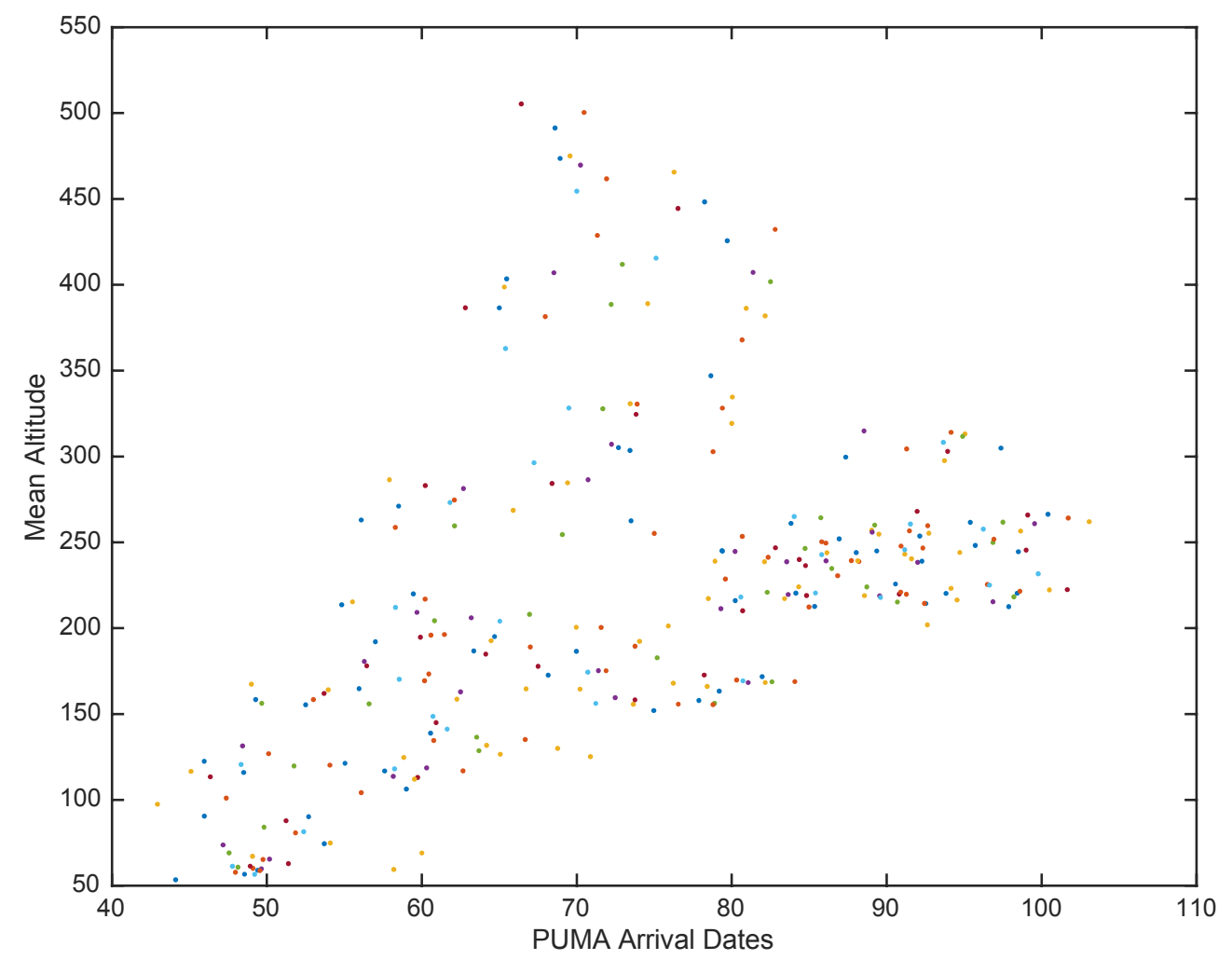




\section{Ruby-Throated hummingbirds (RUTH)}

Ruby-throated Hummingbirds data show a strong spatial structure which is mainly due to the northbound migration process of hummingbirds. The latitudinal structure is strongly evident, however, there is some evidence of longitudinal structure too. The side-by-side boxplots below show all the data (over 10 years of 2001-2010) for each spatial grid cell. Cells are numbered 1-30 with 1, 2, and 3 as the lowest latitudinal portions of the grid.

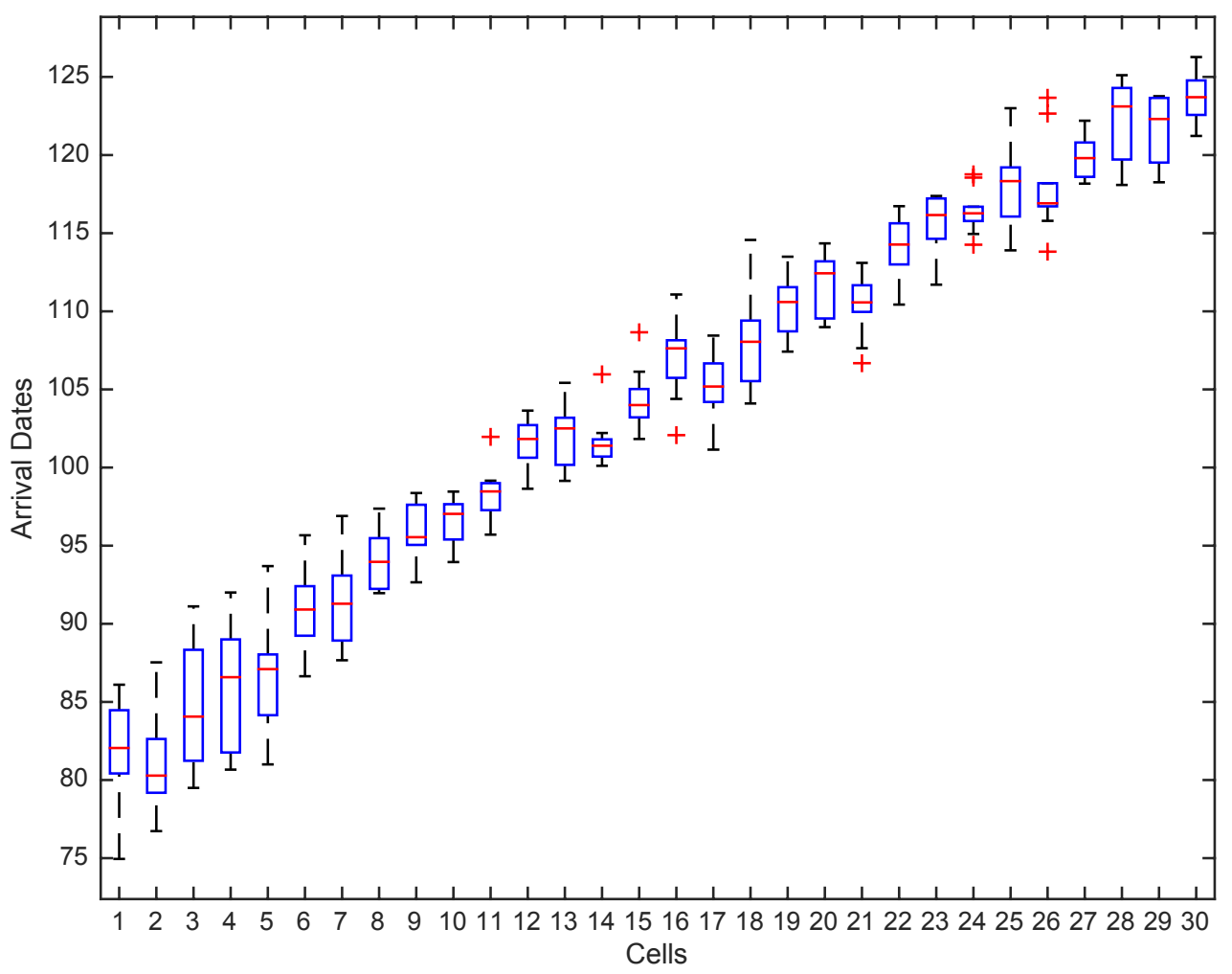


The temporal trends for each of the grid cells shows non-linear behavior. For brevity only odd-numbered cells are shown below. Each plot shows the mean of observations over the period 2001-2010 for a grid cell.
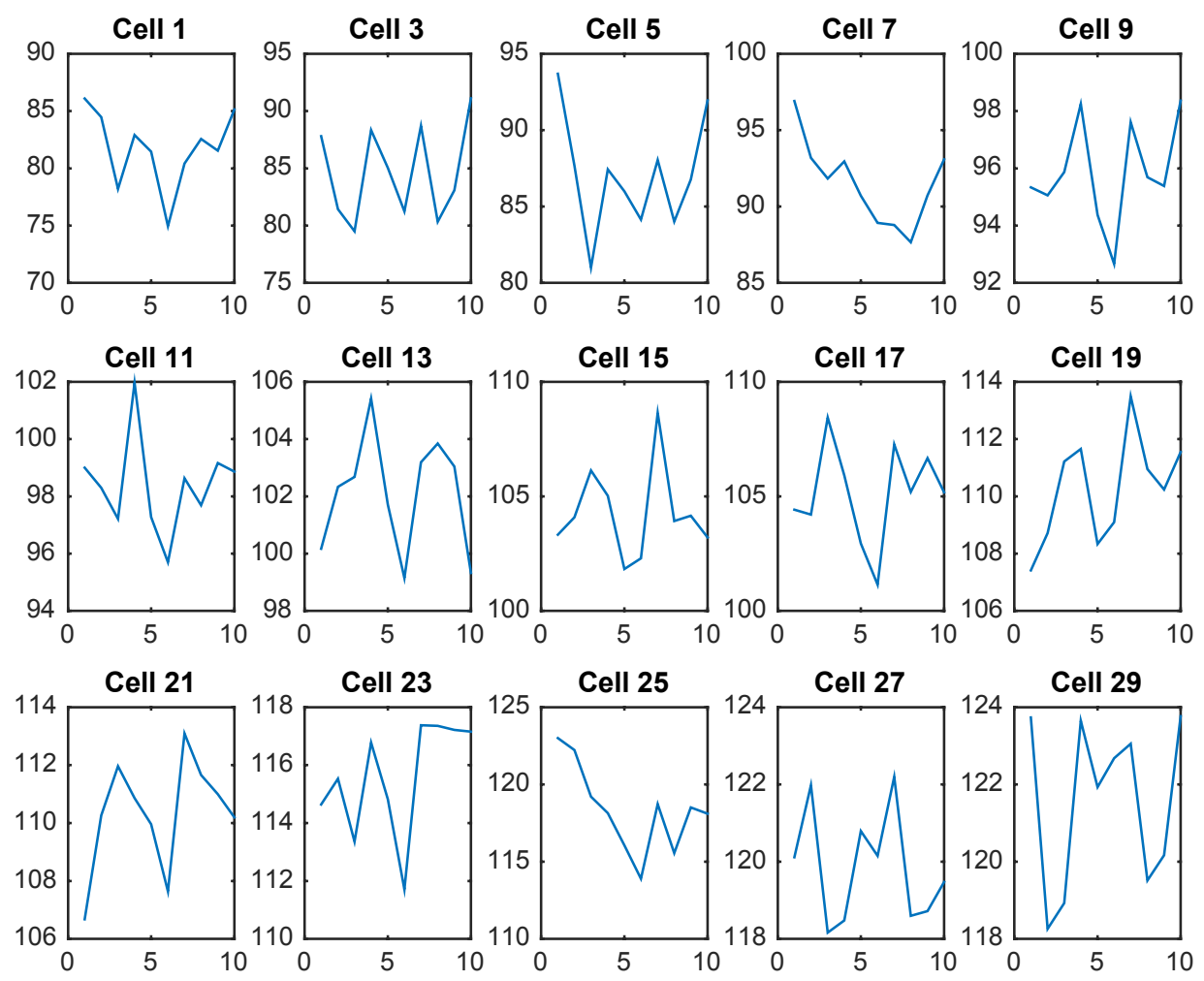
Plot of Jan-Feb Temperature versus Ruby-throated Hummingbirds Arrival Data:

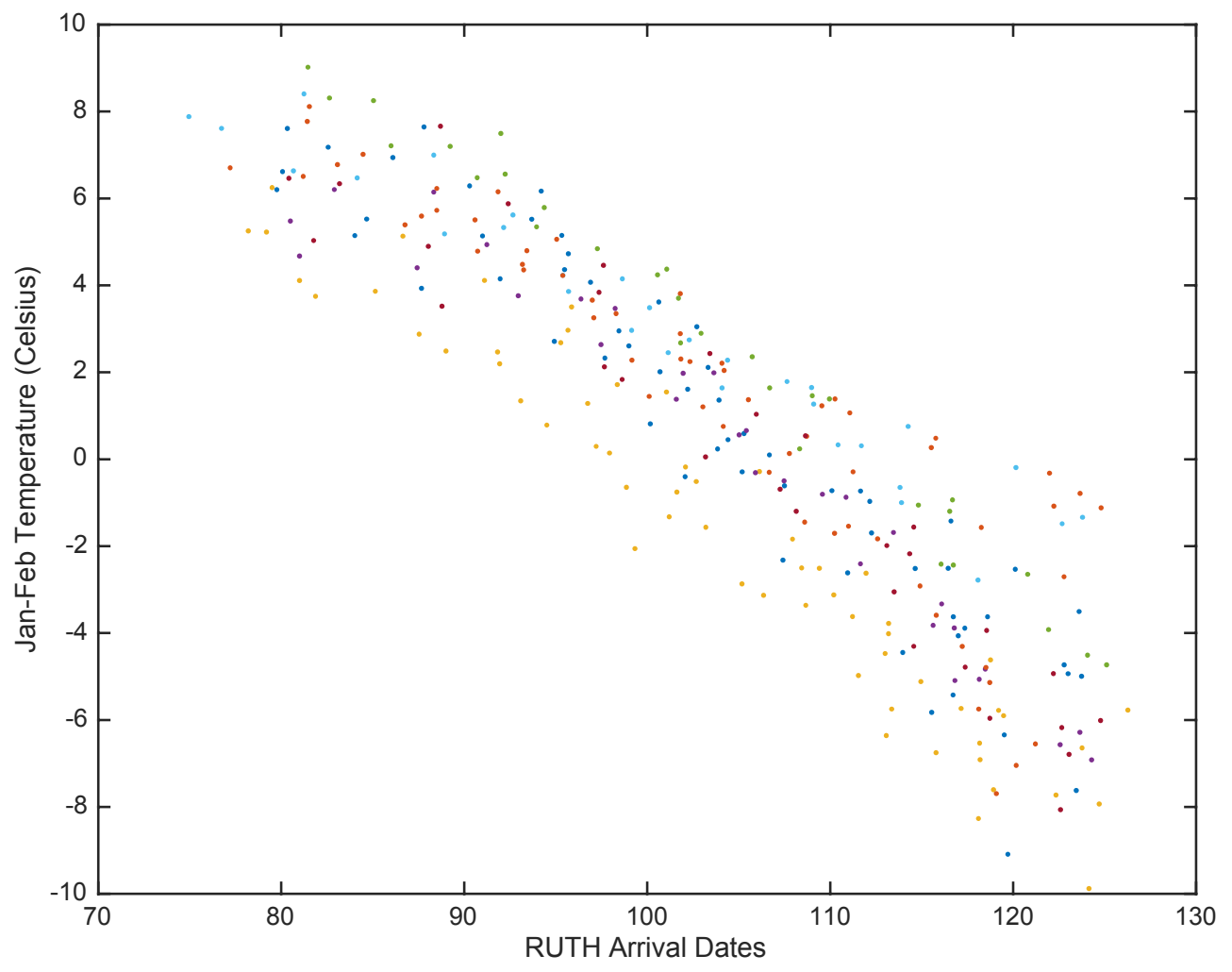


Plot of Sampling Effort versus Ruby-throated Hummingbirds Arrival Data:

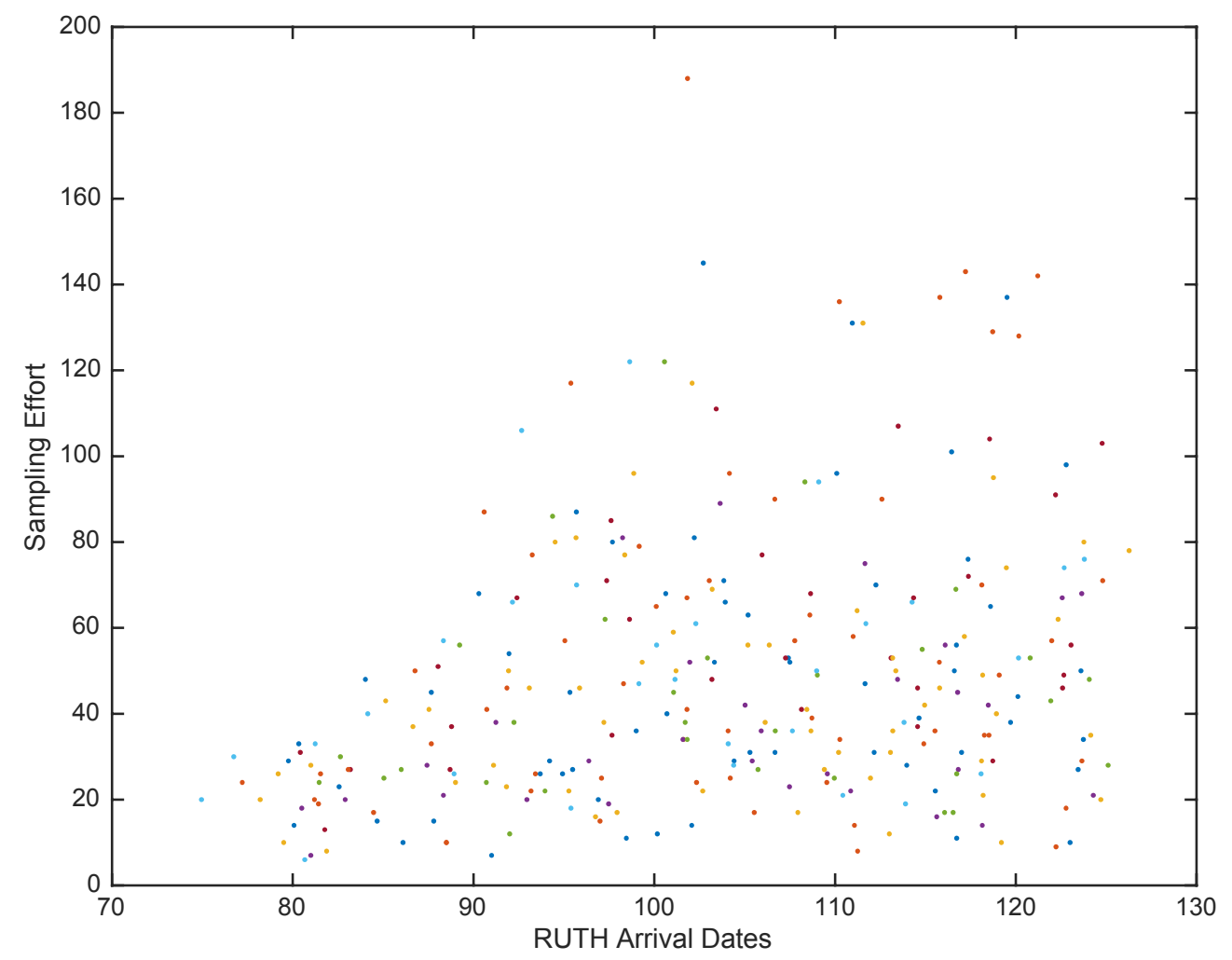


Plot of Mean Altitude versus Ruby-throated Hummingbirds Arrival Data:

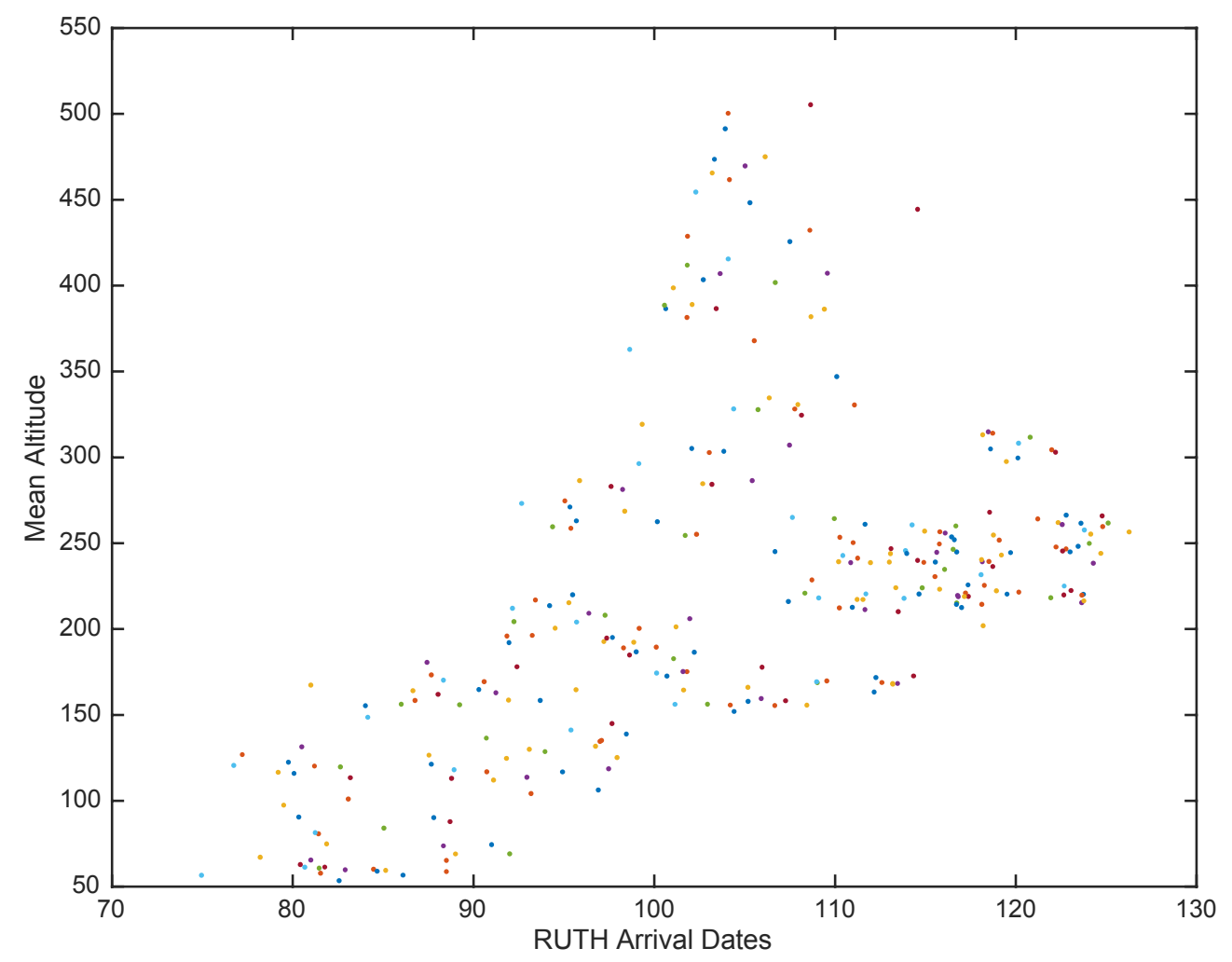


Winter Northern Atlantic Oscillation (WNAO)

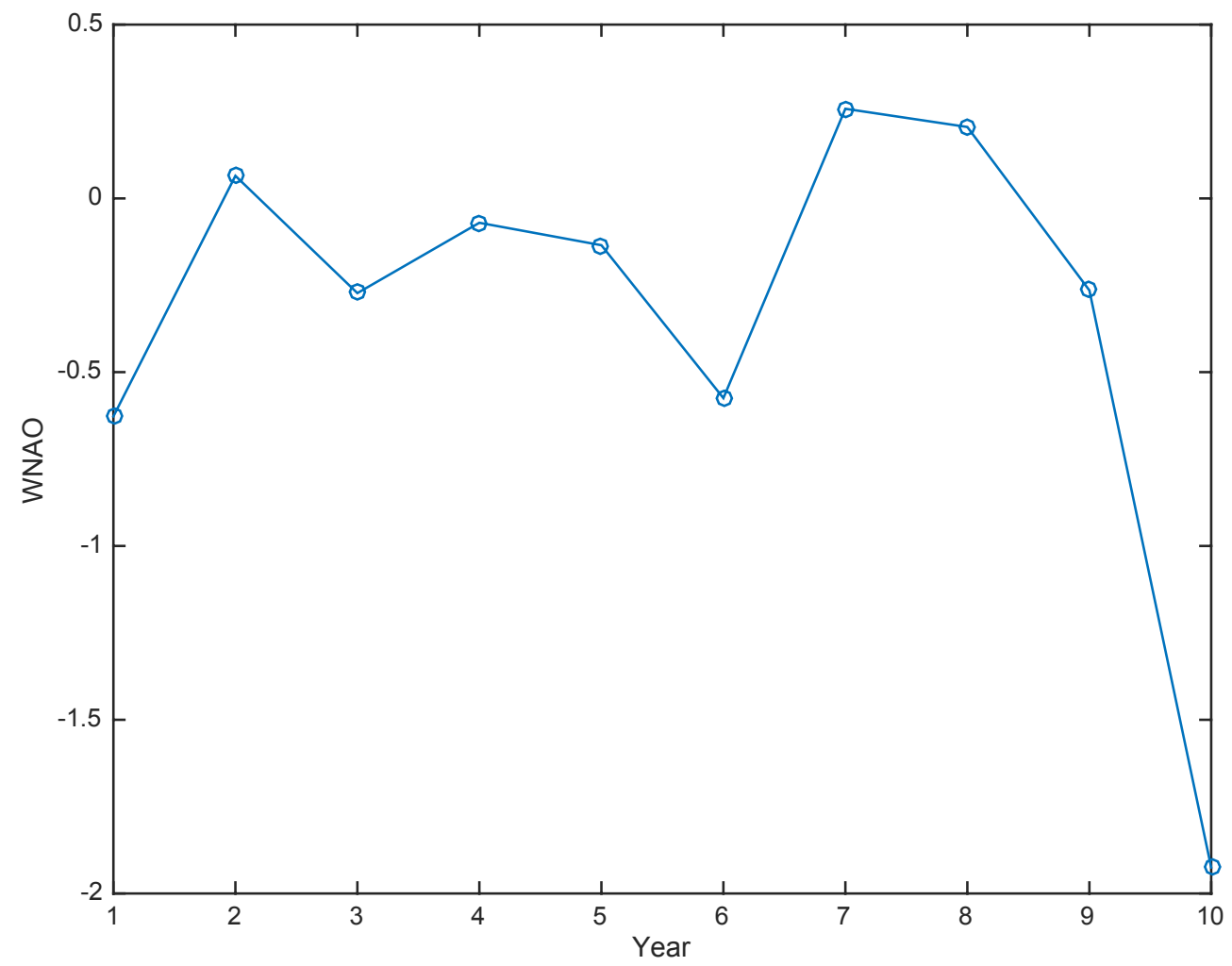

